Marquette University

e-Publications@Marquette

4-2019

\title{
Mental Health Symptoms and The Reintegration Difficulty of Military Couples Following Deployment: A Longitudinal Application of The Relational Turbulence Model
}

\author{
Leanne K. Knobloch \\ University of Illinois - Urbana-Champaign \\ Lynne M. Knobloch-Fedders \\ Marquette University, lynne.knobloch-fedders@marquette.edu \\ Jeremy B. Yorgason \\ Brigham Young University
}

Follow this and additional works at: https://epublications.marquette.edu/psych_fac

Part of the Psychology Commons

\section{Recommended Citation}

Knobloch, Leanne K.; Knobloch-Fedders, Lynne M.; and Yorgason, Jeremy B., "Mental Health Symptoms and The Reintegration Difficulty of Military Couples Following Deployment: A Longitudinal Application of The Relational Turbulence Model" (2019). Psychology Faculty Research and Publications. 464.

https://epublications.marquette.edu/psych_fac/464 
Marquette University

e-Publications@Marquette

\section{Psychology Faculty Research and Publications/College of Arts and Sciences}

This paper is NOT THE PUBLISHED VERSION; but the author's final, peer-reviewed manuscript. The published version may be accessed by following the link in the citation below.

Journal of Clinical Psychology, Vol. 75, No. 4 (April 2019): 742-765. DOI. This article is (C) Wiley and permission has been granted for this version to appear in e-Publications@Marquette. Wiley does not grant permission for this article to be further copied/distributed or hosted elsewhere without the express permission from Wiley.

\section{Mental Health Symptoms and The Reintegration Difficulty of Military Couples Following Deployment: A Longitudinal Application of The Relational Turbulence Model}

Leanne K. Knobloch

Department of Communication, University of Illinois, Urbana, Illinois

Lynne M. Knobloch-Fedders

Department of Counselor Education and Counseling Psychology, Marquette University, Milwaukee, Wisconsin

Jeremy B. Yorgason

School of Family Life, Brigham Young University, Provo, Utah 


\section{Abstract \\ Objective}

Understanding the factors that predict the reintegration difficulty of military couples during the postdeployment transition has important implications for theory, research, and practice. Building on the logic of the relational turbulence model, this paper evaluates the relationship processes of reunion uncertainty and reintegration interference from a partner as mediators of the connection between people's mental health symptoms and their difficulty with reintegration after deployment.

\section{Method}

Dyadic longitudinal data were collected from 555 US military couples once per month for 8 consecutive months.

\section{Results}

Findings mapped the trajectory of reintegration difficulty and suggested reunion uncertainty and reintegration interference from a partner as mediators of the link between people's depressive and posttraumatic stress symptoms and the magnitude of their reintegration difficulty.

\section{Conclusion}

These results highlight relationship processes as a key domain of intervention to preserve the well-being of military couples during the postdeployment transition.

No matter how much military couples look forward to a service member's return home, the transition from deployment to reintegration can be more difficult than portrayed by the popular press (Gorman, Blow, Ames, \& Reed, 2011; Howard \& Prividera, 2015; Karakurt, Christiansen, MacDermid Wadsworth, \& Weiss, 2013). Returning service members may have trouble reconciling their former way of life with their new experiences (Balderrmana-Durbin et al., 2017; Brenner et al., 2015), at-home partners may have problems ceding their autonomy (Faber, Willerton, Clymer, MacDermid, \& Weiss, 2008; Knobloch, Basinger, Wehrman, Ebata, \& McGlaughlin, 2016), and both individuals may have difficulty rejuvenating their connection (Karakurt et al., 2013; Knobloch \& Theiss, 2012).

Difficulty with reintegration refers to the personal and relational stressors that military families experience upon homecoming (Chandra et al., 2011; Chandra et al., 2010; Knobloch, Ebata, McGlaughlin, \& Ogolsky, 2013). Delineating the predictors of reintegration difficulty among returning service members and at-home partners is important for advancing theory about transitions in relationships (e.g., Solomon, Knobloch, Theiss, \& McLaren, 2016) and identifying evidence-based guidelines to help military couples navigate reunion (e.g., Bommarito, Sherman, Rudi, Mikal, \& Borden, 2017; Sherman, Larsen, \& Borden, 2015).

We draw on the relational turbulence model to identify predictors of reintegration difficulty among military couples after deployment (Solomon \& Theiss, 2011). The model has illuminated transitions as diverse as adapting to parenthood, grappling with infertility, coping with breast cancer, and adjusting to empty nest (Solomon et al., 2016). Guided by the model's logic (Knobloch \& Theiss, 2011), we theorize about relationship processes as mediators of the association between people's mental health symptoms and their difficulty with reintegration. Then, we test our reasoning using data from an eight-wave study of reuniting military couples.

\section{REINTEGRATION DIFFICULTY DURING THE POSTDEPLOYMENT TRANSITION}

A growing body of work has investigated the well-being of returning service members and at-home partners after homecoming (Bommarito et al., 2017; Currier, Lisman, Harris, Tait, \& Erbes, 2013; Sherman et al., 2015). 
The emerging evidence suggests that both mental health symptoms (Balderrmana-Durbin et al., 2017; Gibbs, Clinton-Sherrod, \& Johnson, 2012) and relationship processes (Knobloch, Ebata, McGlaughlin, \& Ogolsky, 2013) predict adjustment upon reunion, but these literature are largely separate and would be enriched by synthesis. We seek to fill an important gap by considering relationship processes as mediators of the connection between people's mental health symptoms and their difficulty with reintegration.

\subsection{Mental health symptoms}

Both returning service members and at-home partners experience symptoms of depression, anxiety, and posttraumatic stress during the transition from deployment to the reunion (Gorman et al., 2011; Kim, Thomas, Wilk, Castro, \& Hoge, 2010; Milliken, Auchterlonie, \& Hoge, 2007). Although these mental health symptoms frequently co-occur (e.g., Spinhoven, Pennix, van Hemert, de Rooij, \& Elzinga, 2014), we consider them separately to facilitate a comprehensive examination.

Military couples experiencing depressive, anxiety, and posttraumatic stress symptoms are likely to encounter problems following deployment. For example, military personnel (Blais, Thompson, \& McCreary, 2009) and athome partners (Chandra et al., 2011; Knobloch, Ebata, McGlaughlin, \& Ogolsky, 2013) with symptoms of psychological distress report more challenges during reintegration. Similarly, returning service members with symptoms of depression and posttraumatic stress report more problems adjusting to family life (Sayers, Farrow, Ross, \& Oslin, 2009) and more conflict with others (Gibbs et al., 2012). Together, these findings highlight mental health symptoms as a predictor of the reintegration difficulty of military couples upon reunion.

\subsection{Relationship processes}

Relationship processes also may play a role in people's difficulty with reintegration during the postdeployment transition. The relational turbulence model is a theoretical framework that identifies relationship processes at work during times of transition (Solomon \& Knobloch, 2004; Solomon \& Theiss, 2011). The model defines transitions as periods in the lifespan of relationships that require people to adapt to changing conditions (Solomon et al., 2016), and it argues that transitions can be filled with upheaval (Solomon \& Theiss, 2011). More than 15 years of research has tested and refined the model's logic across a variety of transitions (Knobloch \& Theiss, 2018; Solomon \& Theiss, 2011).

The model specifies two relationship processes instrumental to the experience of turmoil during times of transition: relational uncertainty and interference from a partner (Solomon \& Theiss, 2011). Relational uncertainty is how sure or unsure an individual is about the nature of a relationship (Knobloch \& Theiss, 2010). Interference from a partner occurs when a partner blocks an individual's ability to achieve an everyday goal (Solomon \& Theiss, 2011).

\subsubsection{Reunion uncertainty}

After being reunited following deployment, individuals grapple with questions about how to reintegrate their lives, manage household stressors, adjust to personality changes, navigate sexual intimacy, gauge the service member's well-being, and communicate effectively (Knobloch \& Theiss, 2012). Collectively, these issues represent reunion uncertainty, formally defined as relational uncertainty individuals experience about negotiating the transition from deployment to reintegration (Knobloch, McAninch, Abendschein, Ebata, \& McGlaughlin, 2016).

The model posits that individuals who are unable to make sense of their relationship during times of transition will experience upheaval (Knobloch \& Theiss, 2010; Solomon \& Theiss, 2011). By extension, reunion uncertainty is likely to correspond with reintegration difficulty upon homecoming after deployment. Prior work suggests support for this claim with respect to several markers of turmoil. Cross-sectional data show that people experiencing relational uncertainty, in general, during the postdeployment transition report less relationship 
satisfaction (Knobloch \& Theiss, 2011), more aggressive communication (Theiss \& Knobloch, 2013), and less responsiveness from their partner (Theiss \& Knobloch, 2014). Longitudinal data indicate that relational uncertainty, in general, coincides with more reintegration difficulty during the first 3 months after homecoming (Knobloch, Ebata, McGlaughlin, \& Ogolsky, 2013), and reunion uncertainty, in particular, corresponds with more topic avoidance (Knobloch, Ebata, McGlaughlin, \& Theiss, 2013) and more relationship upheaval (Knobloch, McAninch, et al., 2016). In sum, both theory and research suggest reunion uncertainty as a predictor of reintegration difficulty.

\subsubsection{Reintegration interference from a partner}

Assimilating a service member back into domestic life after deployment yields many opportunities for partners to hinder each other's goals. Reuniting individuals report a partner's interference in everyday routines, domestic tasks, decision-making, autonomy, parenting, personality shifts, social networks and social activities, and spending time together (Knobloch \& Theiss, 2012). We label these issues reintegration interference from $a$ partner to denote the hindrances from a partner specifically tied to the postdeployment transition.

The model contends that individuals whose everyday goals are disrupted by a partner will encounter turmoil during times of transition (Solomon \& Theiss, 2011). Accordingly, military couples experiencing reintegration interference from a partner may have trouble adjusting upon homecoming. Studies measuring interference from a partner, in general, are compatible with this idea across several indicators of upheaval. Recently reunited individuals experiencing interference from a partner judge their relationship to be less satisfying (Knobloch \& Theiss, 2011), appraise their partner as less responsive to their needs (Theiss \& Knobloch, 2014), and communicate in ways that are less open and more aggressive (Knobloch \& Theiss, 2017; Theiss \& Knobloch, 2013). Moreover, interference from a partner is positively associated with problems readjusting during the first 3 months after homecoming (Knobloch, Ebata, McGlaughlin, \& Ogolsky, 2013). Hence, both theory and research imply that reintegration interference from a partner predicts people's difficulty with reintegration.

\subsection{Combined effects of mental health symptoms and relationship processes}

Up to this point, we have considered people's mental health symptoms and relationship processes in isolation, but our goal is integration. We extend the logic of the relational turbulence model to theorize that relationship processes may mediate the effects of people's mental health symptoms on their difficulty with reintegration during the postdeployment transition. Mental health symptoms complicate relating in a variety of ways (e.g., Whisman \& Robustelli, 2016). To the extent that mental health symptoms spark questions about involvement and create opportunities for hindrance (e.g., Knobloch \& Knobloch-Fedders, 2010; Knobloch \& Theiss, 2011), mental health symptoms may cause adjustment problems during the transition by heightening people's reunion uncertainty and reintegration interference from a partner. In other words, mental health symptoms may lead military couples to question the nature of their relationship and impede each other's everyday goals (Knobloch, Ebata, McGlaughlin, \& Olgosky, 2013; Knobloch \& Theiss, 2011), which in turn may escalate their difficulty with reintegration. Evidence of mediation would pave the way for theoretical and clinical advances by identifying reunion uncertainty and reintegration interference from a partner as pathways through which mental health symptoms may contribute to adjustment problems upon reunion.

Three cross-sectional studies speak to the possibility of mediation. Within investigations of civilian couples, relational uncertainty mediated the association between people's depressive symptoms and both their relationship satisfaction (Knobloch \& Knobloch-Fedders, 2010) and their reluctance to discuss sensitive topics (Knobloch, Sharabi, Delaney, \& Suranne, 2016). Within a sample of military personnel, relational uncertainty and interference from a partner mediated the negative association between depressive symptoms and relationship 
satisfaction (Knobloch \& Theiss, 2011). This limited cross-sectional evidence highlights the need for a more rigorous test via all three mental health symptoms and both relationship processes across the transition.

Our goal is to synthesize theorizing about people's difficulty with reintegration during the postdeployment transition. Based on the logic of the relational turbulence model and extant research, we expect that people's mental health symptoms (Hypothesis 1), reunion uncertainty (Hypothesis 2), and reintegration interference from a partner (Hypothesis 3 ) predict more difficulty with reintegration at homecoming $(\mathrm{H} 1 \mathrm{a}, \mathrm{H} 2 \mathrm{a}$, and $\mathrm{H} 3 \mathrm{a}$ ) and over time $(\mathrm{H} 1 \mathrm{~b}, \mathrm{H} 2 \mathrm{~b}$, and $\mathrm{H} 3 \mathrm{~b})$. We also predict that reunion uncertainty (Hypothesis 4 ) and reintegration interference from a partner (Hypothesis 5 ) mediate the association between people's mental health symptoms and their difficulty with reintegration at homecoming ( $\mathrm{H} 4 \mathrm{a}$ and $\mathrm{H} 5 \mathrm{a}$ ) and over time ( $\mathrm{H} 4 \mathrm{~b}$ and $\mathrm{H} 5 \mathrm{~b}$ ).

\section{METHODS}

US military couples provided online data once per month for 8 consecutive months after the reunion, with service members and at-home partners completing the Wave 1 questionnaire within a week after homecoming (see Knobloch, Knobloch-Fedders, \& Yorgason, $\mathbf{2 0 1 8}$ for a report from the same sample). Traditionally the reunion period is defined to last for 6 months (Pincus, House, Christenson, \& Adler, 2001), so we chose 8 months to collect data beyond that window. The procedures were approved by the Institutional Review Boards of our universities and the Human Research Protection Office of the US Army Medical Research and Materiel Command.

We recruited military couples by circulating announcements to (a) military family life professionals across the country, (b) installation newspapers serving all branches, and (c) social media outlets for military families. Military couples were eligible if (a) partners had separate e-mail accounts, (b) one or both partners had been deployed, and (c) both partners completed the first questionnaire within 7 days after homecoming. The recruitment materials invited military couples to sign up for the study by e-mail.

\subsection{Procedures}

After the service member returned home from deployment, we e-mailed each individual an introductory message inviting him or her to confirm consent. As soon as both partners agreed to participate, we enrolled them in the study and e-mailed each person a unique login, a temporary password to be replaced by a permanent password of his or her choice, and a link to the first questionnaire. We sent reminder e-mails on the 4th day and the 6th day after the reunion to individuals who had not yet completed the Wave 1 questionnaire, and the logins expired on the 7th day. Of the 587 military couples who enrolled, 555 completed the Wave 1 questionnaire within the allocated timeframe (94.5\%), and 32 were eliminated because one or both partners did not provide Wave 1 data before the 7-day deadline.

Individuals from the 555 military couples eligible to continue received an e-mail each month on the anniversary of their reunion date with a link to the next questionnaire. During each wave, we sent e-mails on the 4th day and the 6th day reminding people to complete the questionnaire before it closed on the 7th day. Individuals received a $\$ 15$ e-gift card for each wave they completed, along with a bonus $\$ 50$ e-gift card if they completed all waves.

\subsection{Participants}

The sample included 1,110 individuals ( 554 men and 556 women) involved in a romantic relationship ( 554 crosssex couples and 1 same-sex couple). Participants lived in 44 US states, the District of Columbia, and Guam. They identified as Caucasian (81\%), Latino/a (10\%), African American (4\%), Asian or Pacific Islander (3\%), or American Indian or Alaskan Native (2\%). They ranged in age from 19 to 59 years old $(M d n=30.00$ years, $M=31.18$ years, $S D=6.39$ years). Their level of education included some high school $(1 \%)$, 
high school graduate (13\%), some college (31\%), associate's degree (15\%), bachelor's degree (28\%), or advanced graduate degree (12\%).

Most military couples were married (95\%), involved in their first marriage (77\%), cohabiting upon reunion (96\%), and parents (71\%). The average length of their romantic relationship was 8.43 years

$(M d n=7.00$ years, $S D=5.40$ years). Most military couples had an annual household income of $\$ 21,000$ to $\$ 40,000(23 \%), \$ 41,000$ to $\$ 60,000(32 \%)$, or $\$ 61,000$ to $\$ 80,000(18 \%)$.

Most returning service members were men (99\%). They were affiliated with the US Army (40\%), Navy, (21\%), Marines (18\%), Air Force (10\%), Army National Guard (8\%), Air National Guard (2\%), or Coast Guard (1\%). Some returning service members reported on their first deployment (30\%), but others had completed one (24\%) or more (two $=17 \%$, three $=13 \%$, four $=8 \%$, five or more $=8 \%$ ) prior deployments. The average length of their deployment was 7.71 months ( $S D=2.31$ months), and the primary mission of their deployment was combat $(60 \%)$, peacekeeping $(17 \%)$, training $(15 \%)$, relief $(3 \%)$, or undisclosed $(5 \%)$. The majority of at-home partners were women (99\%). Most at-home partners were civilians (88\%), but others were current $(5 \%)$ or former $(7 \%)$ military personnel themselves.

On average, individuals completed the Wave 1 questionnaire 4.27 days ( $M d n=4.00$ days and $S D=1.81$ days) after homecoming. Participation rates were satisfactory across waves (Wave $2=91 \%$, Wave $3=92 \%$, Wave $4=88 \%$, Wave $5=89 \%$, Wave $6=88 \%$, Wave $7=86 \%$, and Wave $8=88 \%$ ). At some point during the study, $32 \%$ of returning service members and $31 \%$ of at-home partners reported participating in a formal or informal program, workshop, or support group to help military couples after deployment.1

\subsection{Measurement strategy}

We selected closed-ended measures that demonstrated sound psychometric properties in prior research. For the multi-item scales without available population norms, we conducted a confirmatory factor analysis to verify the unidimensionality of the factor structure with model fit criteria set at CFI $>0.950$ and RMSEA $<0.060$ (as per Hu \& Bentler, 1999). We assessed two core covariates and 18 secondary covariates for the sake of comprehensiveness.

\subsection{Measures of the covariates}

\subsubsection{Combat exposure during deployment}

We assessed combat exposure during deployment as a core covariate because of its strong connection to mental health symptoms (e.g., Fritch, Mishkind, Reger, \& Gahm, 2010). Returning service members responded to Keane et al.'s (1989) Combat Exposure Scale at Wave 1, and following Renshaw, Rodrigues, and Jones (2008, p. 588), at-home partners responded to the same items at Wave 1 with instructions to provide their best understanding of their partner's experiences during deployment. Sample items included: (a) went on combat patrols, (b) fired rounds at the enemy, and (c) was in danger of being injured or killed ( $0=$ never, $4=51$ or more times ). We computed a score for each individual as the average of the responses to the seven items $(M=0.51, S D=0.64$, range $=0.00-4.00, \alpha=0.75, \mathrm{CFI}=0.964, \mathrm{RMSEA}=0.058)$.

\subsubsection{Relationship satisfaction}

Given evidence that relationship satisfaction among military couples corresponds with both mental health symptoms (Renshaw et al., 2008) and relationship processes (Knobloch \& Theiss, 2011; Theiss \& Knobloch, 2014), we included people's Wave 1 relationship satisfaction as a core covariate to account for variability in dyadic functioning. Example items from the 4-item Couples Satisfaction Index (Funk \& Rogge, 2007) included: (a) please indicate the degree of happiness, all things considered, of your relationship $(0=$ extremely unhappy, 6 = perfect) and (b) how rewarding is your relationship with your partner? $(0=$ not at all, 
$5=$ completely $)$. The measure was calculated as the sum of the responses $(M=17.20, S D=3.32$, range $=2.00-$ 21.00, $\alpha=0.83, \mathrm{CFI}=0.987, \mathrm{RMSEA}=0.051) .2$

\subsubsection{Secondary covariates}

Closed-ended items measured 18 secondary covariates indexing individual, methodological, relationship, and military characteristics at Wave 1 . The individual attributes were (a) sex, (b) race, (c) age, and (d) education. The methodological characteristics were (a) number of days elapsed between reunion and participation in Wave 1 , and (b) version of the measures of depressive and anxiety symptoms (described in the following section). The relationship attributes were (a) household income, (b) relationship length, (c) marital status, (d) prior marriage for the returning service member, (e) prior marriage for the at-home partner, (f) living together in the same residence upon reunion, and (g) the presence of children. The military characteristics were (a) branch, (b) dualmilitary couple status, (c) first versus multiple deployments, (d) deployment length, and (e) mission type.

\subsection{Measures of the independent variables}

\subsubsection{Depressive symptoms}

Participants completed one of two measures of depressive symptoms at Wave 1 . The first half of the sample ( $n=268$ couples) received the Beck Depression Inventory-II (BDI-II; Beck, Steer, \& Brown, 1996), but because of the considerable licensing fees required to administer the BDI-II, the second half of the sample ( $n=287$ couples) received the Center for Epidemiologic Studies Depression Scale Revised (CESD-R; Eaton, Smith, Ybarra, Muntaner, \& Tien, 2004). Participants rated the severity of a list of symptoms (21 for the BDI-II and 20 for the CESD-R). Sample items from the CESD-R included: (a) I could not shake off the blues, (b) nothing made me happy, and (c) I felt depressed.

We put the scales on a common metric by calculating the percent of maximum possible score (POMP) after summing responses across items (Cohen, Cohen, Aiken, \& West, 1999). The POMP metric is superior to other conversion strategies for three reasons. First, it employs a simple linear transformation tied to the scale's original units. Second, it is not dependent on the sample or the population at large. Third, it outperforms other strategies for comparing different measures of the same construct (Cohen et al., 1999). Independent samples $t$ tests showed no difference between the POMP scores for the two versions of the measure for athome partners, $t(553)=-0.35, p=0.728$, but returning service members reported less depressive symptoms on the BDI-II than the CESD-R, $t(553)=-2.09, p=0.037$. Consequently, we controlled for the version of the measure in our substantive analyses.

The average POMP score for depressive symptoms was 11.84 (SD $=12.93$, range $=0-100$, BDI-II $\alpha=0.92$, CESD$\mathrm{R} \alpha=0.90$ ), with 158 individuals (14\%) reporting scores that met or exceeded the clinical cutoffs for mild to moderate depression (Beck et al., 1996; Radloff, 1977).

\subsubsection{Anxiety symptoms}

People responded to one of two scales measuring anxiety symptoms at Wave 1 . The first half of the sample ( $n=268$ couples) completed the 21-item Beck Anxiety Inventory (BAl; Beck, Epstein, Brown, \& Steer, 1988). To reduce licensing costs, the second half of the sample ( $n=287$ couples) completed the 14-item anxiety subscale of the Depression, Anxiety, and Stress Scale (DASS; Lovibond \& Lovibond, 1995). Both scales asked participants to rate how much they were bothered by symptoms during the past week. Example items from the DASS included: (a) feeling terrified, (b) difficulty breathing, and (c) feeling close to panic.

We converted the two measures into a common metric using POMP scaling procedures $(M=6.80, S D=10.27$, range $=0-90$, BAI $\alpha=0.90$, DASS $\alpha=0.83$ ). Fifteen percent of the sample ( $n=162$ individuals) met or exceeded the clinical cutoffs for mild to moderate anxiety at Wave 1 (Beck et al., 1988; Lovibond \& Lovibond, 1995). Both returning service members, $t(553)=2.21, p=0.028$, and at-home partners, $t(553)=4.86, p<0.001$, reported 
higher POMP scores on the BAI than the DASS, so we covaried the version of the measure in our substantive analyses.

\subsubsection{Posttraumatic stress symptoms}

Individuals responded to the 17-item Posttraumatic Stress Checklist (Weathers, Litz, Herman, Huska, \& Keane, 1993) at Wave 1 . Returning service members completed the military version (PCL-M) by rating the degree to which they had experienced symptoms related to stressful military experiences during the past month. At-home partners completed the civilian version (PCL-C), which is identical except that it refers to stressful experiences in general. Sample items from the PCL-C included: (a) feeling very upset when something reminded you of a stressful experience; (b) repeated, disturbing memories, thoughts, or images of a stressful experience; and (c) avoiding activities or situations because they reminded you of a stressful experience ( $1=$ not at all, $5=$ severely). We summed the items to form the measure $(M=25.90, S D=11.57$, range $=17-85, \alpha=0.93)$. In total, $9 \%$ of the sample ( $n=102$ individuals) reported scores that met or exceeded the clinical cutoffs for mild to moderate posttraumatic stress (Ruggiero, Del Ben, Scotti, \& Rabalais, 2003).

\subsubsection{Reunion uncertainty}

Participants reported their Wave 1 reunion uncertainty via Knobloch, McAninch, et al.'s (2016) measure.3 Six reverse-scored unidimensional items were prefaced by the stem "How certain are you about...?" $(1=$ completely uncertain, 6 = completely certain): (a) how to readjust to being together, (b) how to redistribute household chores, (c) how to get to know each other again, (d) how to be sexually intimate after the time apart, (e) how to assess your partner's health and well-being, and (f) how to communicate with your partner. We formed the measure by averaging the items $(M=2.09, S D=1.04$, range $=1-6, \alpha=0.92, C F I=0.984, \mathrm{RMSEA}=0.051)$.

\subsubsection{Reintegration interference from a partner}

Individuals responded to Knobloch, McAninch, et al.'s (2016) measure at Wave 1. Six unidimensional items began with the stem "My partner..." ( 1 = strongly disagree, 6 = strongly agree): (a) disrupts my everyday routine and schedule, (b) interferes with my ability to make my own decisions, (c) makes me feel smothered, (d) has become a different person since the deployment, (e) disrupts my social life with family and friends, and (f) makes me wish we had more time to spend together. The measure was computed as the average of the items $(M=2.19, S D=0.88$, range $=1-6, \alpha=0.72, C F I=0.980$, RMSEA $=0.054) .4$

\subsection{Measure of the dependent variable}

\subsubsection{Difficulty with reintegration}

Participants reported their difficulty with reintegration at each wave via Chandra et al.'s (2011) measure. Six unidimensional items completed the stem "Since I/my partner returned home from deployment, I have ..." ( 1 = strongly disagree, 7 = strongly agree): (a) had problems getting to know my partner again, (b) had difficulty adjusting to having my partner be part of my daily routine, (c) had trouble dealing with my partner's mood changes, (d) worried about the possibility of another deployment, (e) had problems figuring out who to turn to for advice, and ( $f$ ) had trouble rebalancing household tasks. We calculated the variable by averaging the items (Wave $1 M=2.54, S D=1.31$, range $=1-7, \alpha=0.79, \mathrm{CFI}=0.977$, RMSEA $<0.060$ ).

\section{RESULTS}

\subsection{Preliminary analyses}

In a first preliminary analysis, we computed paired samples $t$ tests comparing the Wave 1 reports of returning service members (RSM; $n=555$ ) versus at-home partners (AHP; $n=555$ ). Results for the core covariates showed that returning service members reported more combat exposure during deployment than at-home partners thought they had experienced (see Table 1). Findings for the independent and dependent variables revealed 
that at-home partners, compared with returning service members, reported more mental health symptoms, reunion uncertainty, and difficulty with reintegration.

Table 1. Paired samples $t$ tests comparing returning service members and at-home partners at Wave 1

\begin{tabular}{|l|l|l|l|l|l|l|}
\hline & $\begin{array}{l}\text { Returning service } \\
\text { members }\end{array}$ & & $\begin{array}{l}\text { At-home } \\
\text { partners }\end{array}$ & & \\
\hline & Range & $M$ & $S D$ & $M$ & $S D$ & $t(554)$ \\
\hline Combat exposure & $0-4$ & 0.54 & 0.64 & 0.48 & 0.64 & $2.97^{* *}$ \\
\hline Relationship satisfaction & $2-21$ & 17.27 & 3.08 & 17.12 & 3.54 & 0.94 \\
\hline Depressive symptoms & $0-100$ & 10.16 & 11.36 & 13.52 & 14.13 & $-4.90^{* * *}$ \\
\hline Anxiety symptoms & $0-90$ & 5.00 & 8.35 & 8.59 & 11.61 & $-6.59^{* * *}$ \\
\hline $\begin{array}{l}\text { Posttraumatic stress } \\
\text { symptoms }\end{array}$ & $17-85$ & 24.21 & 10.15 & 27.59 & 12.63 & $-5.45^{* * *}$ \\
\hline Reunion uncertainty & $1-6$ & 2.02 & 0.98 & 2.16 & 1.09 & $-2.85^{* *}$ \\
\hline Reintegration interference & $1-6$ & 2.18 & 0.90 & 2.20 & 0.87 & -0.36 \\
\hline Difficulty with reintegration & $1-7$ & 2.46 & 1.31 & 2.63 & 1.31 & $-2.80^{* *}$ \\
\hline
\end{tabular}

$N=555$ military couples.

$* * p<0.01$.

$* * * p<0.001$.

We also examined Wave 1 bivariate correlations (see Table 2). For both returning service members and at-home partners, mental health symptoms, reunion uncertainty, reintegration interference from a partner, and difficulty with reintegration were positively correlated and shared negative associations with relationship satisfaction. $\mathbf{5}$

Table 2. Bivariate correlations at Wave 1 for returning service members, at-home partners, and military couples

\begin{tabular}{|l|l|l|l|l|l|l|l|l|}
\hline & $\mathrm{V} 1$ & $\mathrm{~V} 2$ & $\mathrm{~V} 3$ & $\mathrm{~V} 4$ & $\mathrm{~V} 5$ & $\mathrm{~V} 6$ & $\mathrm{~V} 7$ & $\mathrm{~V} 8$ \\
\hline $\begin{array}{l}\text { V1: Combat } \\
\text { exposure }\end{array}$ & $\underline{0.75^{* * *}}$ & $-0.10^{*}$ & $0.12^{* *}$ & $0.14^{* *}$ & $0.25^{* * *}$ & $0.11^{*}$ & 0.06 & 0.08 \\
\hline $\begin{array}{l}\text { V2: Relationship } \\
\text { satisfaction }\end{array}$ & -0.04 & $\underline{0.37^{* * *}}$ & $-0.22^{* * *}$ & $-0.23^{* * *}$ & $-0.19^{* * *}$ & $-0.61^{* * *}$ & $-0.42^{* * *}$ & $-0.45^{* * *}$ \\
\hline $\begin{array}{l}\text { V3: Depressive } \\
\text { symptoms }\end{array}$ & 0.07 & $-0.33^{* * *}$ & $\underline{0.20^{* * *}}$ & $0.65^{* * *}$ & $0.68^{* * *}$ & $0.37^{* * *}$ & $0.28^{* * *}$ & $0.36^{* * *}$ \\
\hline $\begin{array}{l}\text { V4: Anxiety } \\
\text { symptoms }\end{array}$ & 0.06 & $-0.18^{* * *}$ & $0.64^{* * *}$ & $\underline{0.20^{* * *}}$ & $0.70^{* * *}$ & $0.29^{* * *}$ & $0.21^{* * *}$ & $0.32^{* * *}$ \\
\hline $\begin{array}{l}\text { V5: } \\
\begin{array}{l}\text { Posttraumatic } \\
\text { stress symptoms }\end{array}\end{array}$ & 0.05 & $-0.30^{* * *}$ & $0.73^{* * *}$ & $0.73^{* * *}$ & $\underline{0.19^{* * *}}$ & $0.28^{* * *}$ & $0.20^{* * *}$ & $0.33^{* * *}$ \\
\hline $\begin{array}{l}\text { V6: Reunion } \\
\text { uncertainty }\end{array}$ & 0.05 & $-0.60^{* * *}$ & $0.44^{* * *}$ & $0.23^{* * *}$ & $0.37^{* * *}$ & $\underline{0.33^{* * *}}$ & $0.49^{* * *}$ & $0.63^{* * *}$ \\
\hline $\begin{array}{l}\text { V7: Reintegration } \\
\text { interference }\end{array}$ & 0.05 & $-0.50^{* * *}$ & $0.42^{* * *}$ & $0.30^{* * *}$ & $0.44^{* * *}$ & $0.55^{* * *}$ & $\underline{0.20^{* * *}}$ & $0.63^{* * *}$ \\
\hline $\begin{array}{l}\text { V8: Difficulty with } \\
\text { reintegration }\end{array}$ & $0.09 *$ & $-0.50^{* * *}$ & $0.52^{* * *}$ & $0.35^{* * *}$ & $0.47^{* * *}$ & $0.70^{* * *}$ & $0.64^{* * *}$ & $\underline{0.37^{* * *}}$ \\
\hline
\end{tabular}

Note. $N=555$ returning service members, at-home partners, or military couples. Wave 1 bivariate correlations for returning service members appear above the diagonal, Wave 1 bivariate correlations for at-home partners appear below the diagonal, and Wave 1 within-couple correlations appear on the diagonal and are underlined. $* p<0.05$.

$* * p<0.01$.

$* * * p<0.001$. 


\subsection{Substantive analyses}

We performed the substantive analyses in four steps using structural equation modeling to estimate dyadic growth curves (Kenny, Kashy, \& Cook, 2006; Peugh, DiLillo, \& Panuzio, 2013). First, we examined the trajectory of reintegration difficulty over time. Next, we evaluated mental health symptoms and relationship processes as predictors of reintegration difficulty separately and then together. Finally, we examined relationship processes as mediators.

\subsubsection{Mapping the trajectory of reintegration difficulty}

In a descriptive first step, we estimated an unconditional model without predictors to illuminate the trajectory of reintegration difficulty across the eight waves of the study. The unconditional model included dyadic growth curves for returning service members and at-home partners and contained correlations (a) between the intercepts and slopes within couples and (b) between the residuals within couples at each wave (see Figure 1).

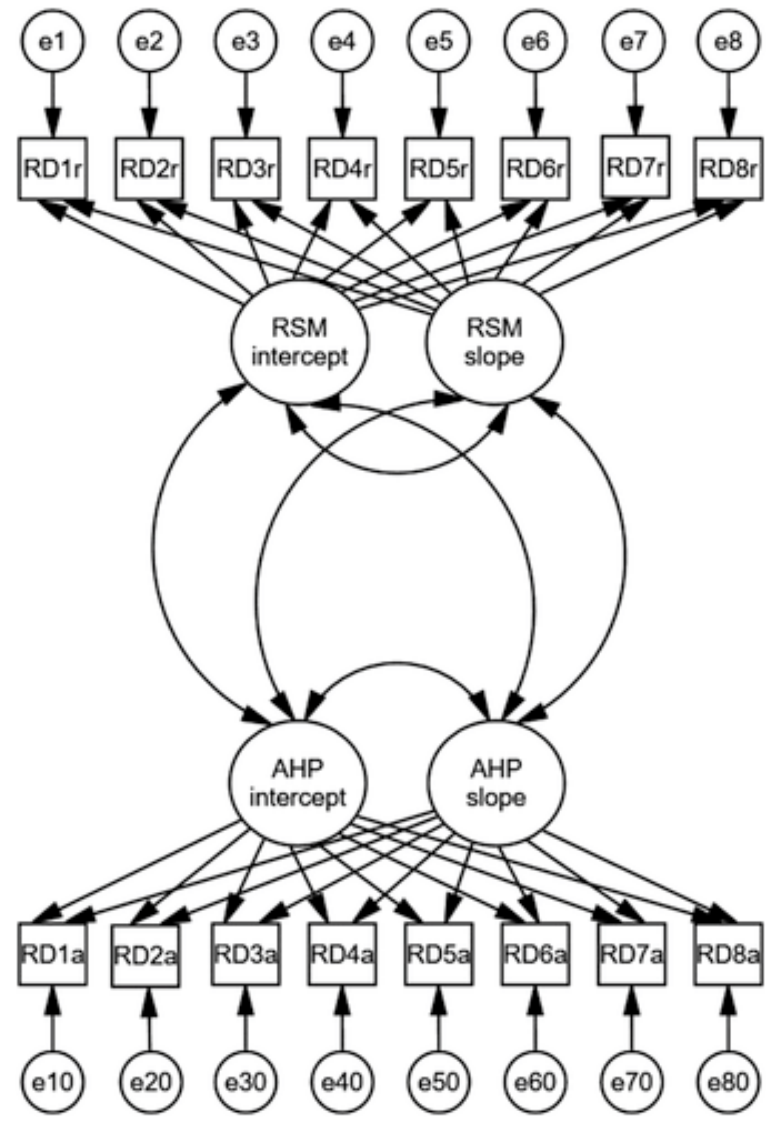

Figure 1 Unconditional dyadic growth curve model. For the sake of parsimony, the diagram omits the residual correlations across returning service members and at-home partners. AHP: at-home partner; RD: reintegration difficulty; RSM: returning service member

Findings showed that a linear decrease in reintegration difficulty was statistically significant in the estimated trajectory for both returning service members and at-home partners (see Figure $\mathbf{2}$ and Table $\mathbf{3}$ ). Both the intercepts and the linear slopes contained variability and were positively correlated between partners. Returning service members and at-home partners differed in their intercepts (Wald test $=13.91, p<0.001$ ) but not their linear slopes (Wald test $=2.25, p=0.134$ ). 


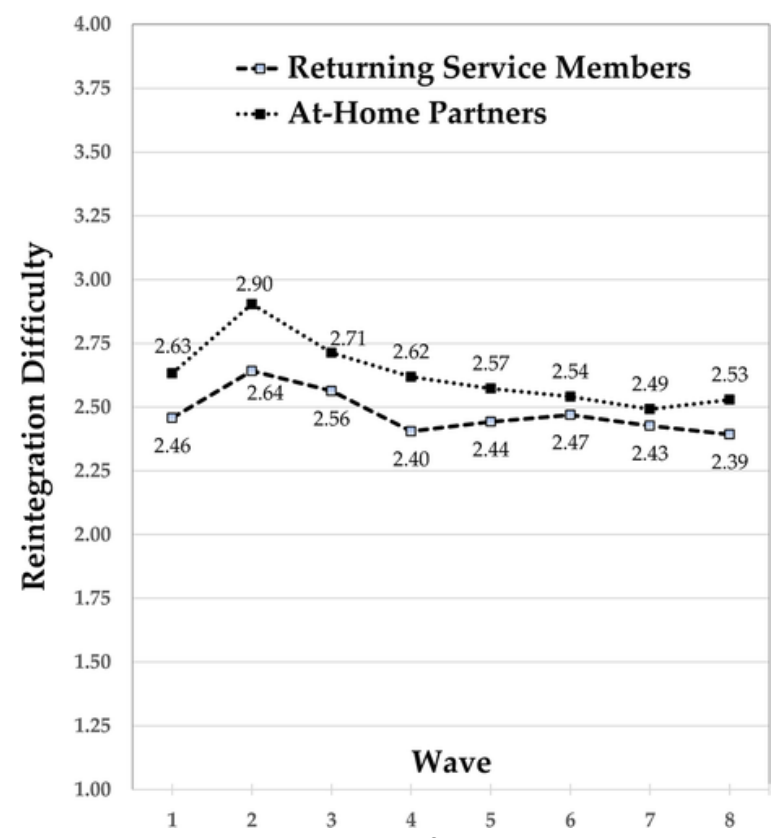

Figure 2 Observed means for the reintegration difficulty of returning service members and at-home partners plotted across waves [Color figure can be viewed at wileyonlinelibrary.com]

Table 3. Growth parameters for the unconditional model predicting difficulty with reintegration

\begin{tabular}{|l|l|l|l|l|}
\hline & Difficulty with reintegration & & & \\
\hline & Returning service members & & At-home partners & \\
\hline & Estimate & Variance & Estimate & Variance \\
\hline Intercept & $2.55^{* * *}$ & $1.15^{* * *}$ & $2.77^{* * *}$ & $1.37^{* * *}$ \\
\hline Linear slope & $-0.02^{* *}$ & $0.02^{* * *}$ & $-0.04^{* * *}$ & $0.02^{* * *}$ \\
\hline$r$ of intercept and linear slope & $-0.27^{* * *}$ & - & $-0.26^{* * *}$ & - \\
\hline
\end{tabular}

Note. $N=555$ military couples. Model fit: $\chi^{2}(114)=343.58, \mathrm{CFI}=0.96, \mathrm{RMSEA}=0.06[90 \% \mathrm{Cl}=0.05,0.06]$. Within-couple correlations: $r=0.49, p<0.001$ for the intercepts, $r=0.49, p<0.001$ for the linear slopes.

$* * p<0.01$.

$* * * p<0.001$.

The observed means suggested that both returning service members and at-home partners experienced an initial increase in reintegration difficulty followed by a decline over time (see Figure 2). Accordingly, we also evaluated nonlinear change by estimating quadratic slopes in addition to linear slopes, but the quadratic slopes were not significantly different from zero for either returning service members, unstandardized $b=0.00, p=0.60$, or at-home partners, unstandardized $b=0.00, p=0.36$. In sum, people's reintegration difficulty decreased over the eight waves.

\subsubsection{Evaluating the substantive predictors individually}

In a second step, we computed five preliminary conditional growth curve models containing one substantive predictor, the two core covariates, and the 18 secondary covariates. The purpose of these preliminary conditional models was to examine how the mental health symptoms and relationship processes predict difficulty with reintegration in isolation beyond the core covariates and secondary covariates.

We constructed the models to examine both actor effects and partner effects (Kenny et al., 2006) as depicted in Figure 3. More specifically, we modeled the substantive predictors, core covariates, and secondary covariates as 
independent variables predicting each person's intercept and linear slope. 6 We also grand-mean centered the continuous predictors to facilitate interpretation of the intercepts.

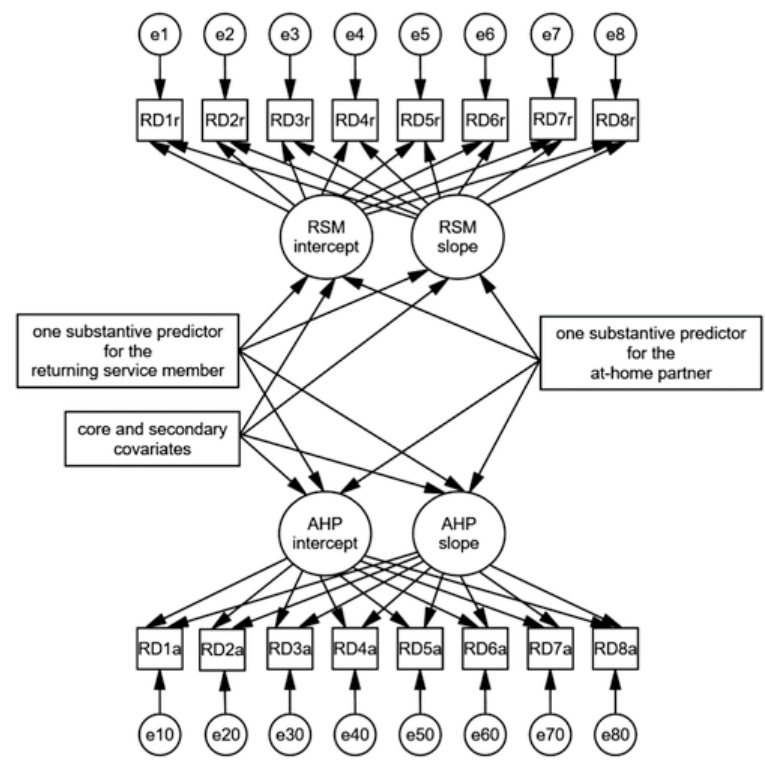

Figure 3 Peliminary conditional dyadic growth curve model. The analysis included one substantive predictor (depressive symptoms, anxiety symptoms, posttraumatic stress symptoms, reunion uncertainty, or reintegration interference from a partner), two core covariates, and 18 secondary covariates. For the sake of parsimony, the diagram omits the latent variable residuals and residual correlations. AHP: at-home partner; RD: reintegration difficulty; RSM: returning service member

The models showed appropriate fit (see Table 4). For the intercepts, actor effects consistent with our predictions revealed that returning service members and at-home partners who reported more mental health symptoms $(\mathrm{H} 1 \mathrm{a})$, reunion uncertainty $(\mathrm{H} 2 \mathrm{a})$, or reintegration interference from a partner $(\mathrm{H} 3 \mathrm{a})$ experienced more difficulty with reintegration at Wave 1 than returning service members and at-home partners who reported less mental health symptoms, reunion uncertainty, or reintegration interference from a partner. For the slopes, actor effects contrary to our hypotheses showed that returning service members who reported more anxiety symptoms or posttraumatic stress symptoms, and at-home partners who reported more depressive symptoms, experienced a steeper decline in difficulty with reintegration over time $(\mathrm{H} 1 \mathrm{~b})$ than those reporting less mental health symptoms. Similarly, returning service members and at-home partners who reported more reunion uncertainty $(\mathrm{H} 2 \mathrm{~b})$ or reintegration interference from a partner $(\mathrm{H} 3 \mathrm{~b})$ experienced a steeper decline in difficulty with reintegration over time than those reporting less reunion uncertainty or reintegration interference from a partner. 
Table 4. Standardized coefficients for the preliminary conditional models predicting difficulty with reintegration

\begin{tabular}{|c|c|c|c|c|c|c|c|c|c|c|}
\hline & $\begin{array}{l}\text { Model 1: } \\
\text { Depressive } \\
\text { symptoms }\end{array}$ & & $\begin{array}{l}\text { Model 2: } \\
\text { Anxiety } \\
\text { symptoms }\end{array}$ & & $\begin{array}{l}\text { Model 3: } \\
\text { Posttraumatic } \\
\text { stress symptoms }\end{array}$ & & $\begin{array}{l}\text { Model 4: } \\
\text { Reunion } \\
\text { uncertainty }\end{array}$ & & $\begin{array}{l}\text { Model 5: } \\
\text { Reintegration } \\
\text { interference }\end{array}$ & \\
\hline & RSM & AHP & RSM & AHP & RSM & AHP & RSM & AHP & RSM & AHP \\
\hline $\begin{array}{l}\text { Actor predictor of } \\
\text { intercepts }\end{array}$ & $0.36 * * *$ & $0.48 * * *$ & $0.33^{* * *}$ & $0.32 * * *$ & $0.35^{* * *}$ & $0.41 * * *$ & $0.63 * * *$ & $0.67 * * *$ & $0.54 * * *$ & $0.53 * * *$ \\
\hline $\begin{array}{l}\text { Actor predictor of } \\
\text { slopes }\end{array}$ & -0.08 & $-0.16^{*}$ & $-0.14^{*}$ & -0.01 & $-0.14 *$ & -0.09 & $-0.33 * * *$ & $-0.39 * * *$ & $-0.21 * *$ & $-0.27 * * *$ \\
\hline $\begin{array}{l}\text { Partner predictor } \\
\text { of intercepts }\end{array}$ & $0.10^{*}$ & $0.08 *$ & 0.05 & $0.09 *$ & 0.07 & $0.09 *$ & $0.15^{* *}$ & $0.17 * * *$ & $0.08^{*}$ & 0.08 \\
\hline $\begin{array}{l}\text { Partner predictor } \\
\text { of slopes }\end{array}$ & 0.06 & -0.02 & 0.11 & -0.02 & 0.03 & -0.03 & -0.02 & -0.09 & $-0.17^{*}$ & 0.06 \\
\hline$R^{2}$ intercept/slope & $0.43 / 0.13$ & $0.52 / 0.17$ & $0.40 / 0.14$ & $0.42 / 0.15$ & $0.42 / 0.14$ & $0.48 / 0.16$ & $0.56 / 0.19$ & $0.63 / 0.25$ & $0.54 / 0.18$ & $0.53 / 0.20$ \\
\hline
\end{tabular}

Note. AHP: at-home partner; RSM: returning service member.

$N=555$ military couples. Each model included one substantive predictor, two core covariates, and 18 secondary covariates. Fit indices were as follows:

(a) Model 1: $\chi^{2}(450)=780.70, \mathrm{CFI}=0.95, \mathrm{RMSEA}=0.04[90 \% \mathrm{Cl}=0.03,0.04]$; (b) Model $2: \chi^{2}(450)=753.25, \mathrm{CFI}=0.95, \mathrm{RMSEA}=0.04[90 \% \mathrm{Cl}=0.03$,

0.04]; (c) Model 3: $\chi^{2}(450)=763.23, \mathrm{CFI}=0.95, \mathrm{RMSEA}=0.04[90 \% \mathrm{Cl}=0.03,0.04] ;$ (d) Model 4: $\chi^{2}(450)=827.25, \mathrm{CFI}=0.94, \mathrm{RMSEA}=0.04[90 \% \mathrm{Cl}=0.04$,

$0.04]$; and (e) Model 5: $\chi^{2}(450)=862.20, \mathrm{CFI}=0.94, \mathrm{RMSEA}=0.04[90 \% \mathrm{Cl}=0.04,0.05]$.

$* p<0.05$.

$* * p<0.01$

$* * * p<0.001$ 
Partner effects emerged as well (see Table 4). When an individual reported more depressive symptoms or reunion uncertainty, his or her partner reported more difficulty with reintegration at Wave 1. Moreover, when returning service members reported more anxiety symptoms and posttraumatic stress symptoms, at-home partners reported more difficulty with reintegration at Wave 1. Finally, when at-home partners reported more reintegration interference from a partner, returning service members experienced more difficulty with reintegration at Wave 1 and a steeper decline over time.

In total, the predictors accounted for $40-63 \%$ of the variance in the intercepts and $13-25 \%$ of the variance in the slopes. People's mental health symptoms and relationship processes predicted their reintegration difficulty at Wave 1 as expected, but findings for the change in their reintegration difficulty over time were opposite expectations.

\subsubsection{Evaluating the substantive predictors together}

Next, we estimated final conditional models containing the five substantive predictors, two core covariates, and 18 secondary covariates (see Figure 4). Again, we evaluated actor and partner effects and grand-mean centered the continuous predictors.

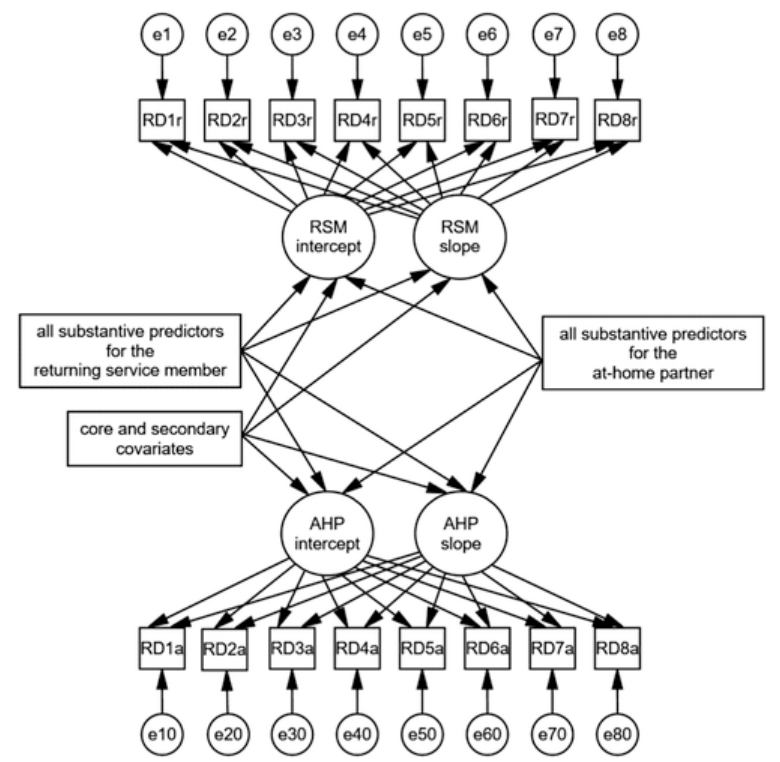

Figure 4 Final conditional dyadic growth curve model. The analysis included five substantive predictors (depressive symptoms, anxiety symptoms, posttraumatic stress symptoms, reunion uncertainty, and reintegration interference from a partner), two core covariates, and 18 secondary covariates. For the sake of parsimony, the diagram omits the latent variable residuals and residual correlations. AHP: at-home partner; RD: reintegration difficulty; RSM: returning service member

Actor effects (see Table 5) indicated that posttraumatic stress symptoms for returning service members, and depressive symptoms for at-home partners, coincided with more difficulty with reintegration at Wave 1 (H1a). For both partners, reunion uncertainty and reintegration interference from a partner were positive predictors at Wave 1 ( $\mathrm{H} 2 \mathrm{a}$ and $\mathrm{H} 3 \mathrm{a}$ ) and corresponded with a steeper decline over time ( $\mathrm{H} 2 \mathrm{~b}$ and $\mathrm{H} 3 \mathrm{~b})$.

Table 5. Standardized coefficients for the final conditional model predicting difficulty with reintegration

\begin{tabular}{|l|l|l|}
\hline & Difficulty with reintegration & \\
\hline & Returning service members & At-home partners \\
\hline Actor predictors of intercepts & & \\
\hline Depressive symptoms & 0.03 & $0.19^{* * *}$ \\
\hline
\end{tabular}




\begin{tabular}{|l|l|l|}
\hline Anxiety symptoms & 0.09 & 0.01 \\
\hline Posttraumatic stress symptoms & $0.15^{* *}$ & 0.08 \\
\hline Reunion uncertainty & $0.42^{* * *}$ & $0.46^{* * *}$ \\
\hline Reintegration interference & $0.39^{* * *}$ & $0.28^{* * *}$ \\
\hline Actor predictors of slopes & & \\
\hline Depressive symptoms & 0.14 & -0.09 \\
\hline Anxiety symptoms & -0.06 & 0.13 \\
\hline Posttraumatic stress symptoms & -0.13 & 0.00 \\
\hline Reunion uncertainty & $-0.28^{* * *}$ & $-0.32^{* * *}$ \\
\hline Reintegration interference & $-0.14^{*}$ & $-0.16^{*}$ \\
\hline$R^{2}$ intercept/slope & $0.73 / 0.26$ & $0.76 / 0.27$ \\
\hline
\end{tabular}

Note. $N=555$ military couples. The models included all of the substantive predictors and covariates. Statistically significant partner effects are reported in the text. Model fit: $\chi^{2}(546)=1,014.28, \mathrm{CFI}=0.93, \mathrm{RMSEA}=0.04[90 \%$ $\mathrm{Cl}=0.04,0.04]$.

$* p<0.05$.

$* * p<0.01$.

$* * * p<0.001$.

Two partner effects surfaced. When an individual experienced reunion uncertainty, his or her partner reported more difficulty with reintegration at Wave 1 (RSM standardized $B=0.11, p<0.05$; AHP $b=0.12, p<0.01$ ). When at-home partners experienced more reintegration interference from a partner, returning service members experienced a steeper decline in their difficulty with reintegration over time ( $\operatorname{RSM} B=-0.20, p<0.05)$.

Together the predictors explained $73-76 \%$ of the variance in reintegration difficulty for the intercepts and $26-$ $27 \%$ for the slopes. In sum, results supported our logic about the magnitude of reintegration difficulty ( $\mathrm{H} 1 \mathrm{a}, \mathrm{H} 2 \mathrm{a}$, and $\mathrm{H} 3 \mathrm{a}$ ) but contradicted our logic about the change over time ( $\mathrm{H} 1 \mathrm{~b}, \mathrm{H} 2 \mathrm{~b}$, and $\mathrm{H} 3 \mathrm{~b}) .7$

\subsubsection{Tests of mediation}

In a final step, we evaluated the indirect actor and partner effects of mental health symptoms on difficulty with reintegration through relational uncertainty and reintegration interference from a partner. We employed a bootstrap approach using 5,000 draws to estimate indirect effects and bias-corrected confidence intervals (Hayes, 2013).

Mediation actor effects, but not mediation partner effects, emerged for both depressive and posttraumatic stress symptoms (see Figure 5). For both partners, depressive symptoms had indirect effects on the intercepts through reunion uncertainty (RSM unstandardized $a b=0.009, p=0.001,95 \% \mathrm{Cl}[0.005,0.016]$; AHP $a b=0.011, p<0.001,95 \% \mathrm{Cl}[0.006,0.018])$ and reintegration interference from a partner (RSM $a b=0.010, p=0.006,95 \% \mathrm{Cl}[0.004,0.017]$; AHP $a b=0.004, p=0.035,95 \% \mathrm{Cl}[0.001,0.009])$. For at-home partners, posttraumatic stress symptoms had indirect effects on the intercept through reintegration interference from a partner (AHP $a b=0.006, p=0.002,95 \% \mathrm{Cl}[0.003,0.011]$ ). These results imply mediation for the intercepts ( $\mathrm{H} 4 \mathrm{a}$ and $\mathrm{H} 4 \mathrm{~b}$ ) but not the slopes ( $\mathrm{H} 4 \mathrm{~b}$ and $\mathrm{H} 5 \mathrm{~b}) .8$ 

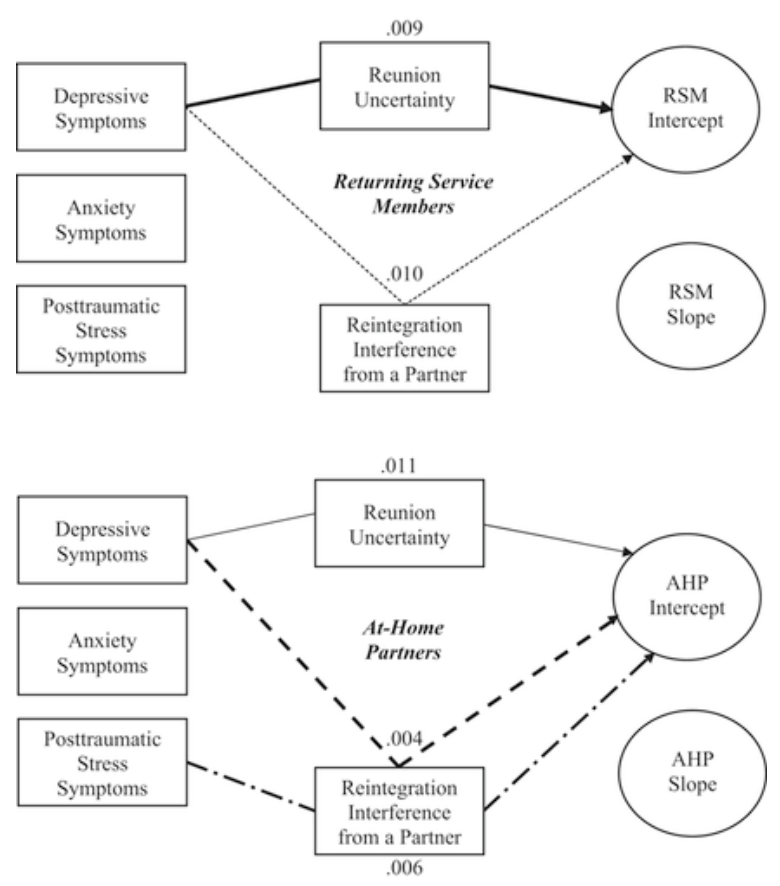

Figure 5 Indirect associations of mental health symptoms through reunion uncertainty and reintegration interference from a partner predicting reintegration difficulty. The indirect effects are depicted by lines of the same pattern connecting three variables. Unstandardized estimates of the indirect effects are reported next to the mediator. AHP: at-home partner; RD: reintegration difficulty; RSM: returning service member

\section{DISCUSSION}

In contrast to media depictions of homecoming as the start of a happily-ever-after storyline, some scholars speculate that reunion can be harder for military families to navigate than deployment itself (Huebner, Mancini, Wilcox, Grass, \& Grass, 2007; Mmari, Roche, Sudhinaraset, \& Blum, 2009). We sought to advance the literature by conceptually and empirically synthesizing predictors of people's difficulty with reintegration. Data from an 8wave longitudinal study of 555 military couples showed that (a) people's difficulty with reintegration was highest at Wave 2 and decreased over time; (b) individuals experiencing more mental health symptoms, reunion uncertainty, and reintegration interference from a partner reported greater difficulty with reintegration at Wave 1 ; and (c) reunion uncertainty and reintegration interference from a partner mediated the effects of people's depressive and posttraumatic stress symptoms at Wave 1 but not over time. We discuss the implications of our findings in the paragraphs that follow.

\subsection{Understanding difficulty with reintegration}

On a descriptive level, our findings map the postdeployment transition (see Figure 2). Speculation existed in the literature that the transition begins with a celebratory phase marked by intense joy and overwhelming excitement (i.e., a honeymoon period) that is replaced by emerging distress as the hassles of everyday life crop up (Milliken et al., 2007; Pincus et al., 2001). Our findings depicted a slightly different trajectory. Military couples in our sample reported a slight uptick in reintegration difficulty at Wave 2 (approximately 4-5 weeks after reunion), but the general pattern was a decline over time. More broadly, our findings speak to the timing of intervention efforts. Rather than offering clinical services immediately after homecoming, when the information may not seem as relevant to military couples, such programs may be most pertinent to them approximately 45 weeks following reunion. 
Our results also offer a more nuanced view of people's mental health symptoms during the postdeployment transition. When examined separately (see Table 4), depressive symptoms, anxiety symptoms, and posttraumatic stress symptoms corresponded with more reintegration difficulty at Wave $1(\mathrm{H} 1 \mathrm{a})$, which coheres with prior work considering them in isolation (Blais et al., 2009; Sayers et al., 2009). When examined together alongside the covariates and relationship processes, posttraumatic stress symptoms for returning service members and depressive symptoms for at-home partners continued to predict their reintegration difficulty at Wave 1, but anxiety symptoms did not (see Table 5). Perhaps these findings point to a distinctive role for some mental health symptoms upon homecoming. For instance, posttraumatic stress symptoms are a common response to the harrowing circumstances that can characterize combat, peacekeeping, and relief missions (Sundin, Fear, Iversen, Rona, \& Wessely, 2010), and depressive symptoms are a common response to the loneliness and worry that can accompany a loved one's journey into harm's way (Meadows et al., 2016; Verdeli et al., 2011). Moreover, depressive symptoms are more prevalent among women (who comprised $99 \%$ of our sample of at-home partners) than men (Kessler, 2003). Clinically, our findings suggest that interventions designed to maximize gains amid limited resources may do well to target posttraumatic stress symptoms for returning service members and depressive symptoms for at-home partners.

Another contribution lies in evaluating the relationship processes emphasized by the relational turbulence model. The model proposes that individuals experience upheaval during times of transition because they are uncertain about their relationship and disrupt each other's daily routines (Solomon \& Theiss, 2011). Both reunion uncertainty $(\mathrm{H} 2 \mathrm{a})$ and reintegration interference from a partner $(\mathrm{H} 3 \mathrm{a})$ predicted the magnitude of people's difficulty with reintegration. These results were remarkably consistent: Not only did they hold for both partners, but they held when the predictors were examined separately (see Table 4) as well as in combination with the covariates, mental health symptoms, and each other (see Table 5). The uniformity across all tests implies that reunion uncertainty and reintegration interference from a partner may play a role in the adjustment of military couples upon reunion.

Our study afforded a rare opportunity to compare people's experiences within couples. Much of the prior work on reunion after deployment has privileged either (a) returning service members separately from at-home partners (Bommarito et al., 2017; Sherman et al., 2015), or (b) individuals rather than military couples (Gorman et al., 2011; Theiss \& Knobloch, 2014). Both sampling strategies can mask the extent to which the experiences of individuals are intertwined within dyads. In our sample, at-home partners reported more mental health symptoms, reunion uncertainty, and reintegration difficulty than returning service members (see Table 1). These findings are consistent with research illustrating the distress of military spouses (Sahlstein, Maguire, \& Timmerman, 2009) and spotlight the importance of ensuring they have adequate social support (Skomorovsky, 2014; see also Easom, Wang, Moore, Wang, \& Bauer, 2018). At the same time, virtually all of the returning service members in our sample were men and the at-home partners were women, so a worthwhile goal for future research is to disentangle whether these findings reflect differences due to deployment or gender.

How individuals fared across the transition was at least partially contingent on each other's well-being. For example, when either person reported more reunion uncertainty, the other person experienced more reintegration difficulty at Wave 1 . Such partner effects highlight the need for more sophisticated theorizing about within-couple dynamics during times of transition (Solomon et al., 2016). They also imply that prevention and intervention efforts should target military couples rather than returning service members or at-home partners in isolation (e.g., Erbes, Polusny, MacDermid, \& Compton, 2008; Sayers, 2011).

An unexpected aspect of our findings involved how people's mental health symptoms and relationship processes predicted changes in reintegration difficulty over time. Opposite hypotheses, more reunion uncertainty $(\mathrm{H} 2 \mathrm{~b})$ and reintegration interference from a partner $(\mathrm{H} 3 \mathrm{~b})$ corresponded with a steeper decline in reintegration 
difficulty across waves. In other words, individuals experiencing more questions and disruptions at homecoming reported a greater drop in adjustment problems over time. A methodological explanation is that the findings are a statistical artifact reflecting the "law of initial values" (Wilder, 1967) such that higher starting values portend a steeper decline over time because those scores have further to fall. Indeed, studies of marriage using growth curve techniques commonly report such a trend via a negative correlation between people's intercept and slope (e.g., Cui \& Donnellan, 2009). Notably, however, the negative correlations between the intercepts and slopes in our data did not ameliorate the magnitude of effects: People experiencing higher levels of reintegration difficulty at Wave 1 still reported higher levels at Wave 8 despite experiencing a more precipitous drop across the latter waves. A conceptual explanation is that military couples who reunite with more acute mental health symptoms and relationship problems may be more likely to seek help, although stigma is still a barrier to care (e.g., Kim et al., 2010; Milliken et al., 2007). Both explanations remain speculative without additional data, so we recommend further research on the mechanisms underlying changes in reintegration difficulty across the transition.

Regarding the primary goal of our study, our data suggested relationship processes as mediators of the link between people's mental health symptoms and the magnitude of their reintegration difficulty (see Figure 5). These findings pave the way for advances in theory, research, and practice. With respect to theory, our results highlight the value of expanding logic about relational turbulence to integrate mental health symptoms (e.g., Knobloch \& Theiss, 2011). With respect to research, our data emphasize the utility of juxtaposing predictors from a variety of domains when examining postdeployment outcomes (e.g., Meadows et al., 2016). With respect to practice, our findings imply that bolstering dyadic well-being could help protect military couples from the harmful effects of mental health symptoms during the transition (Balderrama-Durbin et al., 2017; Erbes et al., 2008). Our results also underscore reunion uncertainty and reintegration interference from a partner as targets of intervention to assist military couples upon homecoming.

Our project expands the relational turbulence model as well. Methodologically, our research design surpasses previous tests of the model in terms of sample size, number of observations, and geographic locale of participants (cf. Knobloch \& Theiss, 2010; Solomon \& Theiss, 2008; Theiss, Estlein, \& Weber, 2013). It also surpasses prior work on the model with military couples in terms of branch affiliation and scope of measurement (cf. Knobloch, McAninch, et al., 2016; Knobloch \& Theiss, 2011). Conceptually, our study is the first to pursue theoretical synthesis among a host of mental health symptoms and relationship processes. Our data imply that the model has some explanatory power for understanding the postdeployment transition. Not only is such confirmation useful for a literature that has been primarily descriptive thus far (Knobloch \& Theiss, 2018), but it also opens the door to sustained contributions via the conceptual organization of findings and the execution of programmatic research.

\subsection{Clinical implications}

Clinically, our findings suggest several empirically grounded recommendations to help military couples upon reunion. First, our results showing that at-home partners reported more challenges than returning service members (see Table 1) emphasize the importance of supporting individuals who stay behind. Given that society at large tends to render the sacrifices of at-home partners largely invisible (e.g., Harrell, 2000), offering clinical services for them is particularly important. Second, our data mapping the trajectory of reintegration difficulty (see Figure 2) imply that clinical efforts may be most germane 4-5 weeks following reunion rather than right after homecoming (when support may not seem necessary) or several months afterward (when support may be less relevant). Clinicians and chaplains involved with sequenced outreach programs, such as the Yellow Ribbon Reintegration Program for National Guard and reserve service members (e.g., Scherrer et al., 2014), should consider the trajectory of reintegration difficulty when timing the delivery of their curriculum. 
With respect to the content of intervention services, our findings point to reunion uncertainty and reintegration interference from a partner as relationship processes to consider-alongside posttraumatic stress symptoms for returning service members and depressive symptoms for at-home partners-when assisting military couples during the postdeployment transition (see Table 5). Clinicians may have success boosting the well-being of military couples upon reunion by helping them work through their questions and troubleshoot disruptions to their everyday goals (e.g., Solomon et al., 2016). More broadly, our results for mediation at Wave 1 (see Figure 5) suggest that relationship support may help buffer military couples from the negative consequences of mental health symptoms after deployment. Finally, because people's reintegration difficulty was predicted by both their own experiences (actor effects) and their partner's experiences (partner effects), clinicians may be most effective by involving both returning service members and at-home partners in treatment (e.g., Erbes et al., 2008).

\subsection{Strengths, limitations, and directions for future research}

Our study possesses both strengths and weaknesses for drawing conclusions about the postdeployment transition. A strength lies in considering a myriad of covariates and independent variables. Juxtaposing three mental health symptoms with two relationship processes, for example, furnished information about their relative predictive power not provided by prior work examining one or two constructs in isolation (e.g., Knobloch, Ebata, McGlaughlin, \& Ogolsky, 2013; Knobloch \& Theiss, 2011). Another advantage is that our sample contained both members of military couples. Compared to previous investigations recruiting individuals (e.g., Brenner et al., 2015; Knobloch \& Theiss, 2011; Sahlstein et al., 2009), our dyadic data revealed both similarities and differences between returning service members versus at-home partners. Third, the study's longitudinal approach permitted mapping of the transition over time in ways not feasible by cross-sectional designs (Knobloch \& Theiss, 2011) or shorter longitudinal designs (Knobloch, Ebata, McGlaughlin, \& Ogolsky, 2013).

Key limitations of our study involve the timing and sequence of data collection. For example, our study began at homecoming rather than before or during deployment. Data collected from military couples before reunion would have permitted us to distinguish between enduring vulnerabilities and emerging stress during the transition (e.g., Blow et al., 2017).9 Second, we built on the logic of the relational turbulence model to position relationship processes as mediators of the association between people's mental health symptoms and their difficulty with reintegration (Knobloch \& Theiss, 2011), yet other orderings are possible. For example, people's reunion uncertainty and reintegration interference from a partner could spark mental health problems, which in turn, could escalate reintegration difficulty (but our data were less compatible with this sequence; see Note 8). Alternatively, people's difficulty with reintegration could contribute to the poorer mental health and worse relationship processes. Future research is needed to examine alternative pathways.

Other limitations stem from the measurement and sampling procedures. With respect to measurement, our study focused on mental health symptoms rather than disorders, so our data do not speak to clinical diagnoses of depression, anxiety, and posttraumatic stress. Moreover, the two halves of the sample completed different measures of depressive symptoms and anxiety symptoms. We converted the measures into a common metric and controlled for the version in the substantive analyses, but determining the superiority of one set over the other was beyond the scope of our investigation. In terms of sampling, active duty military couples comprised $90 \%$ of our sample, which did not permit a reasonable test of whether National Guard and reserve component military couples have unique experiences (e.g., Podlogar et al., 2017). Men comprised 99\% of our sample of returning service members, and women comprised $99 \%$ of our sample of at-home partners, which precluded conclusions about deployment versus gender. More generally, we utilized convenience sampling strategies rather than the more sophisticated random sampling techniques used by recent large-scale investigations of military life (e.g., Meadows et al., 2016), and individuals in our convenience sample reported relatively low levels 
of dysfunction. Population-level data are needed to illuminate the magnitude of reintegration difficulty experienced by returning service members and at-home partners during the transition.

A final direction for future research involves broadening the focus from military couples to military families. Just as our study sought to document the trajectory of reintegration difficulty among returning service members and at-home partners, knowledge gaps exist about how military children experience a parent's homecoming (Meadows et al., 2016). Both parental mental health (Chandra et al., 2010) and marital processes (Knobloch, Knobloch-Fedders, Yorgason, Ebata, \& McGlaughlin, 2017) are likely to play a role in military children's outcomes. Subsequent work that builds on our findings would be helpful for continuing to identify data-driven recommendations to support military families during the postdeployment transition.

\section{CONCLUSION}

The challenges of deployment do not end when service members return home from their mission (Gorman et al., 2011; Karakurt et al., 2013; Theiss \& Knobloch, 2014). We used the relational turbulence model to integrate theorizing about mental health symptoms and relationship processes as predictors of the reintegration difficulty of returning service members and at-home partners upon reunion. Our data tracking the trajectory of reintegration difficulty imply that help may be most relevant to military couples $4-5$ weeks after homecoming. Our results also identify reunion uncertainty and reintegration interference from a partner as relationship processes to address in clinical services.

\section{ACKNOWLEDGMENTS}

The authors are grateful to Bryan Abendschein, Erin Basinger, Daniel Byrne, Hallie Davis, Dale Erdmier, Kelly McAninch, J. Kale Monk, Matthew Muscatella, Matthew Pasquini, Laura Saldivar, Claudia Szczepaniak, Erin Wehrman, and Sylvie Xiaowei Zhuang. This study was supported by the Congressionally Directed Medical Research Programs through the Military Operational Medicine Research Program (Award W81XWH-14-2-0131). The US Army Medical Research Acquisition Activity, 820 Chandler Street, Fort Detrick MD 21702-5014, was the awarding and administering acquisition office. Opinions, interpretations, conclusions, and recommendations are those of the authors and are not necessarily endorsed by the US Department of Defense.

1 We conducted independent samples $t$ tests to examine whether individuals who did versus did not participate in a program at some point during the study differed in their difficulty with reintegration at Wave 1 or Wave 8. At-home partners who did $\left(32 \% ; M_{\mathrm{W} 1}=2.69, S D_{\mathrm{W} 1}=1.34 ; M_{\mathrm{w} 8}=2.66, S D_{\mathrm{W} 8}=1.38\right)$ versus did not $\left(68 \% ; M_{\mathrm{w} 1}=2.61, S D_{\mathrm{w} 1}=1.29 ; M_{\mathrm{w} 8}=2.47, S D_{\mathrm{w} 8}=1.45\right)$ participate in such a program reported similar levels of difficulty with reintegration both at Wave $1, t(553)=0.68, p=0.49$, and at Wave $8, t(499)=1.38, p=0.17$. Conversely, returning service members who participated in such a program (31\%; $M_{\mathrm{w} 1}=2.64, S D_{\mathrm{W} 1}=1.39 ; M_{\mathrm{w} 8}=2.66, S D_{\mathrm{w} 8}=1.47$ ) reported more difficulty with reintegration than those who did not $\left(69 \% ; M_{\mathrm{w} 1}=2.37, S D_{\mathrm{w} 1}=1.26 ; M_{\mathrm{w} 8}=2.25, S D_{\mathrm{w} 8}=1.26\right)$, both at homecoming, $t(553)=2.26, p=0.03$, and at Wave $8, t(469)=3.06, p=0.002$. A reasonable explanation is that returning service members facing greater challenges are more likely to receive services, but our study is not equipped for a comprehensive analysis of help-seeking during the transition. We identify this issue as an important direction for future research.

2 Participants reported their relationship satisfaction at each wave, but their scores were largely stable across time (intraclass correlation $\mathbf{0 . 9 2}$ for returning service members and 0.94 for at-home partners). Accordingly, we streamlined the analyses by controlling for relationship satisfaction only at Wave 1.

3 Our project did not require participants to be parents (unlike the study by Knobloch, McAninch, et al., 2016), so we omitted the item referencing parenting for the measures of reunion uncertainty, reintegration interference from a partner, and difficulty with reintegration.

4 Based on the results of confirmatory factor analyses, we eliminated one item ("makes it harder for me to complete household chores") because of lack of fit. 
5 Given the strong positive bivariate correlations among reunion uncertainty, reintegration interference from a partner, and difficulty with reintegration at Wave 1 (see Table 2), we conducted subsidiary confirmatory factor analyses to examine whether they loaded on the same factor. Findings corroborated them as distinct: Neither the reunion uncertainty items nor the reintegration interference from partner items formed a unidimensional first-order factor when paired with the difficulty with reintegration items for either returning service members or at-home partners.

6 We reduced the number of parameters to be estimated by representing the six categorical secondary covariates as single dummy-coded variables: (a) sex $(1=$ male, $0=$ female $)$; (b) race $(1=$ White, $0=$ NonWhite); (c) version of the measures of depressive symptoms and anxiety symptoms ( $1=\mathrm{BDI}-\mathrm{II}$ and BAl, $0=$ CESD-R, and DASS); (d) marital status ( $1=$ married, $0=$ not married $)$ ( $(\mathrm{e})$ military branch $(1=$ active duty Army, 0 = all other branches); and ( $f$ ) mission during deployment ( 1 = combat mission, $0=$ noncombat mission). Because $99.8 \%$ of the military couples in the sample were heterosexual, we covaried only the sex of the returning service member.

7 The statistical significant results remained largely the same when we repeated the substantive analyses but removed the dummy-coded term controlling for the version of the measures of depressive and anxiety symptoms, but six new effects emerged without the covariate. We followed the more conservative approach by retaining the covariate in reporting the results.

$8 \mathrm{We}$ also evaluated mental health symptoms, rather than relationship processes, as mediators. To that end, we examined the indirect effects of reunion uncertainty and reintegration interference from a partner on difficulty with reintegration through depressive symptoms, anxiety symptoms, and posttraumatic stress symptoms. Findings revealed three indirect actor effects predicting the intercepts, one for returning service members and two for at-home partners, but all three were similar or smaller in size compared with the smallest of the five indirect effects in the hypothesized model. These results favor relationship processes as mediators over mental health symptoms.

9 Our original research design called for a wave of data collection during deployment, but those plans were canceled when the US Central Command issued an order to eliminate human subjects research for service members in theater by May 2014.

\section{REFERENCES}

Balderrama-Durbin, C., Stanton, K., Snyder, D. K., Cigrang, J. A., Talcott, G. W., Smith Slep, A. M., ... Cassidy, D. G. (2017). The risk for marital infidelity across a year-long deployment. Journal of Family Psychology, 31, 629-634. https://doi.org/10.1037/fam0000281

Beck, A. T., Epstein, N., Brown, G., \& Steer, R. A. (1988). An inventory for measuring clinical anxiety: Psychometric properties. Journal of Consulting and Clinical Psychology, 56, 893- 897. https://doi.org/10.1037/002-006X.56.6.893

Beck, A. T., Steer, R. A., \& Brown, G. K. (1996). Manual for the Beck Depression Inventory-II. San Antonio, TX: Psychological Corporation.

Blais, A. R., Thompson, M. M., \& McCreary, D. R. (2009). The development and validation of the Army postdeployment reintegration scale. Military Psychology, 21, 365- 386. https://doi.org/10.1080/08995600902914727

Blow, A. J., Bowles, R. P., Farero, A., Subramaniam, S., Lappan, S., Nichols, E., ... Guty, D. (2017). Couples coping through deployment: Findings from a sample of National Guard families. Journal of Clinical Psychology, 73, 1753- 1767. https://doi.org/10.1002/jclp.22487

Bommarito, R. K., Sherman, M. D., Rudi, J. H., Mikal, J. P., \& Borden, L. M. (2017). Challenges facing military spouses during postdeployment reintegration: A review of the literature and current supports. Military Behavioral Health, 5, 51- 63. https://doi.org/10.1080/21635781.2016.1243494

Brenner, L. A., Betthauser, L. M., Bahraini, N., Lusk, J. L., Terrio, H., Scher, A. I., \& Schwab, K. A. (2015). Soldiers returning from deployment: A qualitative study regarding exposure, coping, and reintegration. Rehabilitation Psychology, 60, 277- 285. https://doi.org/10.1037/rep0000048 
Chandra, A., Lara-Cinisomo, S., Jaycox, L. H., Tanielian, T., Bing, H., Burns, R., \& Ruder, T. (2011). Views from the homefront: The experiences of youth and spouses from military families (Document No. TR-913NMFA). Santa Monica, CA: RAND. https://doi.org/10.1037/e531002011-001

Chandra, A., Lara-Cinisomo, S., Jaycox, L. H., Tanielian, T., Burns, R. M., Ruder, T., \& Han, B. (2010). Children on the homefront: The experience of children from military families. Pediatrics, 125, 16- 25. https://doi.org/10.1542/peds.2009-1180

Cohen, P., Cohen, J., Aiken, L. S., \& West, S. G. (1999). The problem of units and the circumstances for POMP. Multivariate Behavioral Research, 34, 315- 346. https://doi.org/10.1207/S15327906MBR3403 2

Cui, M., \& Donnellan, M. B. (2009). Trajectories of conflict over raising adolescent children and marital satisfaction. Journal of Marriage and Family, 71, 478- 494. https://doi.org/10.1111/j.17413737.2009.00614.x

Currier, J. M., Lisman, R., Irene Harris, J., Tait, R., \& Erbes, C. R. (2013). Cognitive processing of trauma and attitudes toward disclosure in the first six months after military deployment. Journal of Clinical Psychology, 69, 209- 221. https://doi.org/10.1002/jclp.21930

Easom, L. R., Wang, K., Moore, R. H., Wang, H., \& Bauer, L. (2018). Operation family caregiver: Problem-solving training for military caregivers in a community setting. Journal of Clinical Psychology, 74, 536- 553. https://doi.org/10.1002/jclp.22536

Eaton, W. W., Smith, C., Ybarra, M., Muntaner, C., \& Tien, A. (2004). Center for Epidemiologic Studies Depression Scale: Review and revision (CESD and CESD-R). In M. E. Maruish (Ed.), The use of psychological testing for treatment planning and outcomes assessment ( 3rd ed., Vol. 3, pp. 363-377). Mahwah, NJ: Erlbaum.

Erbes, C. R., Polusny, M. A., MacDermid, S., \& Compton, J. S. (2008). Couple therapy with combat veterans and their partners. Journal of Clinical Psychology, 64, 972-983. https://doi.org/10.1002/jclp.20521

Faber, A. J., Willerton, E., Clymer, S. R., MacDermid, S. M., \& Weiss, H. M. (2008). Ambiguous absence, ambiguous presence: A qualitative study of military reserve families in wartime. Journal of Family Psychology, 22, 222- 230. https://doi.org/10.1037/0893-3200.22.2.222

Fritch, A. M., Mishkind, M., Reger, M. A., \& Gahm, G. A. (2010). The impact of childhood abuse and combatrelated trauma on postdeployment adjustment. Journal of Traumatic Stress, 23, 248- 254. https://doi.org/10.1002/its. 20520

Funk, J. L., \& Rogge, R. D. (2007). Testing the ruler with item response theory: Increasing precision of measurement for relationship satisfaction with the Couples Satisfaction Index. Journal of Family Psychology, 21, 572- 583. https://doi.org/10.1037/0893-3200.21.4.572

Gibbs, D. A., Clinton-Sherrod, A. M., \& Johnson, R. E. (2012). Interpersonal conflict and referrals to counseling among married soldiers following return from deployment. Military Medicine, 177, 1178- 1183. https://doi.org/10.7205/milmed-d-12-00008

Gorman, L. A., Blow, A. J., Ames, B. D., \& Reed, P. L. (2011). National Guard families after combat: Mental health, use of mental health services, and perceived treatment barriers. Psychiatric Services, 62, 28- 34. https://doi.org/10.1176/appi.ps.62.1.28

Harrell, M. C. (2000). Invisible women: Junior enlisted Army wives (Document No. MR-1223). Santa Monica, CA: RAND.

Hayes, A. F. (2013). Introduction to mediation, moderation, and conditional process analysis: A regression-based approach. New York, NY: Guilford Press.

Howard, J. W., II, \& Prividera, L. C. (2015). Nationalism and soldiers' health: Media framing of soldiers' returns from deployment. In E. Sahlstein Parcell \& L. M. Webb (Eds.), A communication perspective on the military: Interactions, messages, and discourses ( pp. 217-236). New York, NY: Peter Lang.

Hu, L., \& Bentler, P. M. (1999). Cutoff criteria for fit indices in covariance structure analysis: Conventional criteria versus new alternatives. Structural Equation

Modeling, 6, 1- 55. https://doi.org/10.1080/10705519909540118

Huebner, A. J., Mancini, J. A., Wilcox, R. M., Grass, S. R., \& Grass, G. A. (2007). Parental deployment and youth in military families: Exploring uncertainty and ambiguous loss. Family Relations, 56, 112-122. https://doi.org/10.1111/j.1741-3729.2007.00445.x 
Karakurt, G., Christiansen, A. T., Wadsworth, S. M. M., \& Weiss, H. M. (2013). Romantic relationships following wartime deployment. Journal of Family

Issues, 34, 1427-1451. https://doi.org/10.1177/0192513X12470799

Keane, T. M., Fairbank, J. A., Caddell, J. M., Zimering, R. T., Taylor, K. L., \& Mora, C. A. (1989). Clinical evaluation of a measure to assess combat exposure. Psychological

Assessment, 1, 53- 55. https://doi.org/10.1037/1040-3590.1.1.53

Kenny, D. A., Kashy, D. A., \& Cook, W. L. (2006). Dyadic data analysis. New York, NY: Guilford.

Kessler, R. (2003). Epidemiology of women and depression. Journal of Affective Disorders, 74, 5- 13. https://doi.org/10.1016/S0165-0327(02)00426-3

Kim, P. Y., Thomas, J. L., Wilk, J. E., Castro, C. A., \& Hoge, C. W. (2010). Stigma, barriers to care, and use of mental health services among active duty and National Guard soldiers after combat. Psychiatric Services, 61, 582- 588. https://doi.org/10.1176/appi.ps.61.6.582

Knobloch, L. K., Basinger, E. D., Wehrman, E. C., Ebata, A. T., \& McGlaughlin, P. C. (2016). Communication of military couples during deployment and reunion: Changes, challenges, benefits, and advice. Journal of Family Communication, 16, 160- 179. https://doi.org/10.1080/15267431.2016.1146723

Knobloch, L. K., Ebata, A. T., McGlaughlin, P. C., \& Ogolsky, B. (2013). Depressive symptoms, relational turbulence, and the reintegration difficulty of military couples following wartime deployment. Health Communication, 28, 754- 766. https://doi.org/10.1080/10410236.2013.800440

Knobloch, L. K., Ebata, A. T., McGlaughlin, P. C., \& Theiss, J. A. (2013). Generalized anxiety and relational uncertainty as predictors of topic avoidance during reintegration following military deployment. Communication Monographs, 80, 452-477. https://doi.org/10.1080/03637751.2013.828159

Knobloch, L. K., \& Knobloch-Fedders, L. M. (2010). The role of relational uncertainty in depressive symptoms and relationship quality: An actor-partner interdependence model. Journal of Social and Personal Relationships, 27, 137- 159. https://doi.org/10.1177/0265407509348809

Knobloch, L. K., Knobloch-Fedders, L. M., \& Yorgason, J. B. (2018). Communication of military couples during deployment predicting generalized anxiety upon reunion. Journal of Family Psychology, 32, 12-21. https://doi.org/10.1037/fam0000344

Knobloch, L. K., Knobloch-Fedders, L. M., Yorgason, J. B., Ebata, A. T., \& McGlaughlin, P. C. (2017). Military children's difficulty with reintegration after deployment: A relational turbulence model perspective. Journal of Family Psychology, 31, 542- 552. https://doi.org/10.1037/fam0000299

Knobloch, L. K., McAninch, K. G., Abendschein, B., Ebata, A. T., \& McGlaughlin, P. C. (2016). Relational turbulence among military couples after reunion following deployment. Personal Relationships, 23, 742-758. https://doi.org/10.1111/pere.12148

Knobloch, L. K., Sharabi, L. L., Delaney, A. L., \& Suranne, S. M. (2016). The role of relational uncertainty in topic avoidance among couples with depression. Communication Monographs, 83, 25- 48. https://doi.org/10.1080/03637751.2014.998691

Knobloch, L. K., \& Theiss, J. A. (2010). An actor-partner interdependence model of relational turbulence: Cognitions and emotions. Journal of Social and Personal Relationships, 27, 595-619. https://doi.org/10.1177/0265407510368967

Knobloch, L. K., \& Theiss, J. A. (2011). Depressive symptoms and mechanisms of relational turbulence as predictors of relationship satisfaction among returning service members. Journal of Family Psychology, 25, 470- 478. https://doi.org/10.1037/a0024063

Knobloch, L. K., \& Theiss, J. A. (2012). Experiences of U.S. military couples during the post-deployment transition: Applying the relational turbulence model. Journal of Social and Personal Relationships, 29, 423-450. https://doi.org/10.1177/0265407511431186

Knobloch, L. K., \& Theiss, J. A. (2017). Topic avoidance about deployment upon reunion: Applying the relational turbulence model. Military Behavioral Health, 5, 117-128. https://doi.org/10.1080/21635781.2016.1272013 
Knobloch, L. K., \& Theiss, J. A. (2018). Relational turbulence theory applied to the transition from deployment to reintegration. Journal of Family Theory \& Review, 10, 535- 549. https://doi.org/10.1111/jftr.12281

Lovibond, S. H., \& Lovibond, P. F. (1995). Manual for the Depression Anxiety Stress Scales ( 2nd ed.). Sydney, Australia: Psychology Foundation.

Meadows, S. O., Tanielian, T., Karney, B., Schell, T., Griffin, B. A., Jaycox, L. H., \& Vaughan, C. A. (2016). The Deployment Life Study: Longitudinal analysis of military families across the deployment cycle (Document No. RR-1388-A). Santa Monica, CA: RAND. https://doi.org/10.7249/RR1388

Milliken, C. S., Auchterlonie, J. L., \& Hoge, C. W. (2007). Longitudinal assessment of mental health problems among active and reserve component soldiers returning from the Iraq war. Journal of the American Medical Association, 298, 2141-2148. https://doi.org/10.1001/jama.298.18.2141

Mmari, K., Roche, K. M., Sudhinaraset, M., \& Blum, R. (2009). When a parent goes to war: Exploring the issues faced by adolescents and their families. Youth \& Society, 40, 455- 475. https://doi.org/10.1177/0044118x08327873

Peugh, J. L., DiLillo, D., \& Panuzio, J. (2013). Analyzing mixed-dyadic data using structural equation models. Structural Equation Modeling, 20, 314- 337. https://doi.org/10.1080/10705511.2013.769395

Pincus, S. H., House, R., Christenson, J., \& Adler, L. E. (2001). The emotional cycle of deployment: A military family perspective. U. S. Army Medical Department Journal, 15- 23.

Podlogar, M. C., Houtsma, C., Khazem, L. R., Ringer, F., Mofield, T., Green, B. A., ... Joiner, T. E. (2017). The associations between Army National Guard versus active duty soldier status and perceived burdensomeness, thwarted belongingness, and acquired capability. Journal of Clinical Psychology, 73, 1682- 1691. https://doi.org/10.1002/iclp.22473

Radloff, L. S. (1977). The CES-D scale: A self-report depression scale for research in the general population. Applied Psychological Measurement, 1, 385- 401. https://doi.org/10.1177/014662167700100306

Renshaw, K. D., Rodrigues, C. S., \& Jones, D. H. (2008). Psychological symptoms and marital satisfaction in spouses of Operation Iraqi Freedom veterans: Relationships with spouses' perceptions of veterans' experiences and symptoms. Journal of Family Psychology, 22, 586- 594. https://doi.org/10.1037/0893$\underline{3200.22 .3 .586}$

Ruggiero, K. J., Ben, K. D., Scotti, J. R., \& Rabalais, A. E. (2003). Psychometric properties of the PTSD Checklist Civilian version. Journal of Traumatic Stress, 16, 495- 502. https://doi.org/10.1023/a:1025714729117

Sahlstein, E., Maguire, K. C., \& Timmerman, L. (2009). Contradictions and praxis contextualized by wartime deployment: Wives' perspectives revealed through relational dialectics. Communication Monographs, 76, 421- 442. https://doi.org/10.1080/03637750903300239

Sayers, S. L. (2011). Family reintegration difficulties and couples therapy for military veterans and their spouses. Cognitive and Behavioral Practice, 18, 108- 119. https://doi.org/10.1016/j.cbpra.2010.03.002

Sayers, S. L., Farrow, V. A., Ross, J., \& Oslin, D. W. (2009). Family problems among recently returned military veterans referred for a mental health evaluation. Journal of Clinical Psychiatry, 70, 163- 170. https://doi.org/10.4088/jcp.07m03863

Scherrer, J. F., Widner, G., Shroff, M., Matthieu, M., Balan, S., van den Berk-Clark, C., \& Price, R. K. (2014). Assessment of a post-deployment Yellow Ribbon Reintegration Program for National Guard members and supporters. Military Medicine, 179, 1391- 1397.

Sherman, M. D., Larsen, J., \& Borden, L. M. (2015). Broadening the focus in supporting reintegrating Iraq and Afghanistan veterans: Six key domains of functioning. Professional Psychology: Research and Practice, 46, 355- 365. https://doi.org/10.1037/pro0000043

Skomorovsky, A. (2014). Deployment stress and well-being among military spouses: The role of social support. Military Psychology, 26, 44- 54. https://doi.org/10.1037/mil0000029

Solomon, D. H., \& Knobloch, L. K. (2004). A model of relational turbulence: The role of intimacy, relational uncertainty, and interference from partners in appraisals of irritations. Journal of Social and Personal Relationships, 21, 795- 816. https://doi.org/10.1177/0265407504047838 
Solomon, D. H., Knobloch, L. K., Theiss, J. A., \& McLaren, R. M. (2016). Relational turbulence theory: Explaining variation in subjective experiences and communication within romantic relationships. Human Communication Research, 42, 507-532. https://doi.org/10.1111/hcre.12091

Solomon, D. H., \& Theiss, J. A. (2008). A longitudinal test of the relational turbulence model of romantic relationship development. Personal Relationships, 15, 339- 357. https://doi.org/10.1111/i.14756811.2008.00202.x

Solomon, D. H., \& Theiss, J. A. (2011). Relational turbulence: What doesn't kill us makes us stronger. In W. R. Cupach \& B. H. Spitzberg (Eds.), The dark side of close relationships II ( pp. 197- 216). New York, NY: Routledge.

Spinhoven, P., Penninx, B. W., van Hemert, A. M., de Rooij, M., \& Elzinga, B. M. (2014). Comorbidity of PTSD in anxiety and depressive disorders: Prevalence and shared risk factors. Child Abuse \& Neglect, 38, 1320-1330. https://doi.org/10.1016/j.chiabu.2014.01.017

Sundin, J., Fear, N. T., Iversen, A., Rona, R. J., \& Wessely, S. (2010). PTSD after deployment to Iraq: Conflicting rates, conflicting claims. Psychological Medicine, 40, 367- 382. https://doi.org/10.1017/S0033291709990791

Theiss, J. A., Estlein, R., \& Weber, K. M. (2013). A longitudinal assessment of relationship characteristics that predict new parents' relationship satisfaction. Personal Relationships, 20, 216- 235. https://doi.org/10.1111/i.1475-6811.2012.01406.x

Theiss, J. A., \& Knobloch, L. K. (2013). A relational turbulence model of military service members' relational communication during reintegration. Journal of Communication, 63, 1109-1129. https://doi.org/10.1111/icom.12059

Theiss, J. A., \& Knobloch, L. K. (2014). Relational turbulence and the post-deployment transition: Self, partner, and relationship focused turbulence. Communication Research, 41, 27- 51. https://doi.org/10.1177/0093650211429285

Verdeli, H., Baily, C., Vousoura, E., Belser, A., Singla, D., \& Manos, G. (2011). The case for treating depression in military spouses. Journal of Family Psychology, 25, 488- 496. https://doi.org/10.1037/a0024525

Weathers, F., Litz, B., Herman, D., Huska, J., \& Keane, T. (1993). The PTSD Checklist (PCL): Reliability, validity, and diagnostic utility. Paper presented at the Annual Convention of the International Society for Traumatic Stress Studies, San Antonio, TX.

Whisman, M. A., \& Robustelli, B. L. (2016). Intimate relationship functioning and psychopathology. In K. T. Sullivan \& E. Lawrence (Eds.), The Oxford handbook of relationship science and couple interventions ( pp. 69- 82). New York: Oxford University Press. https://doi.org/10.1093/oxfordhb/9780199783267.013.13

Wilder, J. (1967). Stimulus and response: The law of initial value. Bristol, UK: Wright. https://doi.org/10.1016/B978-1-4831-6797-8.50001-0 